

\section{EXPEDIENTE}

Universidade do Estado do Rio de Janeiro - UERJ

Instituto de Estudos Sociais e Políticos - IESP

\section{CADERNOS DE ESTUDOS SOCIAIS E POLÍTICOS}

www.e-publicacoes.uerj.br/index.php/CESP

\section{COMITÊ EDITORIAL}

Giovana Esther Zucatto, IESP-UERJ

Helio Cannone, IESP-UERJ

Marcelo Borel, IESP-UERJ

Marcia Rangel Candido, IESP-UERJ

Marina Rute Pacheco, IESP-UERJ

Mariane Silva Reghim, IESP-UERJ

Paulo Joaquim Da Silva Rodrigues, IESP-UERJ

Raul Nunes de Oliveira, IESP-UERJ

\section{CAPA, LAYOUT E DIAGRAMAÇÃO}

Marcia Rangel Candido

Raul Nunes de Oliveira

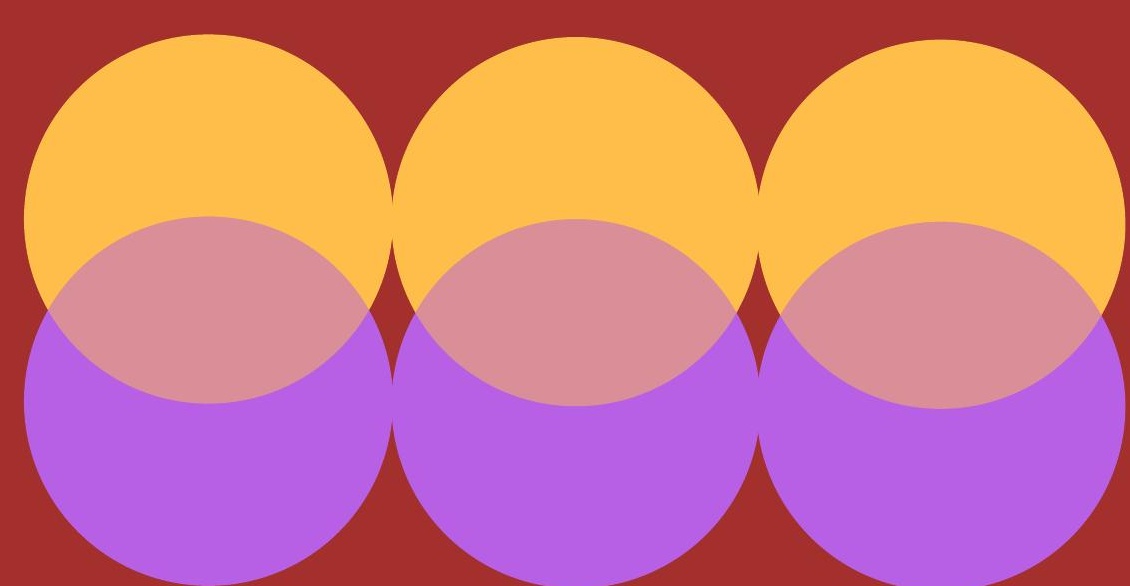


Apresentação

Mariane Silva Reghim e Marcelo Borel

Dossiê

As Expressões Do Racismo Institucional Nas Universidades Federais Do

Estado Do Rio De Janeiro: Mulheres Negras Trabalhadoras e Intelectuais

Cibele da Silva Henriques

Ressignificando As Raças: Os Deuses Pretos e Os Demônios Brancos No Discurso Nacionalista Preto Da Nação Do Islã nos Estados Unidos Da América

Rafael Filter Santos da Silva

Feminismo Negro e a Interseccionalidade de Gênero, Raça e Classe

Eunice Lea de Moraes Lucia Isabel Conceição da Silva

A Corporeidade e a Liberdade: Mulheres Negras e a Coragem De Ser

Joyce Gonçalves Restier da Costa Souza

\section{Artigos}

Os Governos Do PT e As Agências De Rating: Os Percalços De Treze Anos De Relação

Pedro Lange Netto Machado

Apropriação Cultural: Novas Configurações das Identidades na Era da Globalização

Bárbara Lopes Heleno e Rafaella Max Reinhardt

Resenha Crítica: O Segredo como Conceito Político: a propósito de Democracia e Segredo de Norberto Bobbio

Ronaldo Tadeu de Souza 


\title{
A Corporeidade e a Liberdade: Mulheres Negras e a Coragem De Ser
}

\author{
Corporation And Freedom: Black Women And The Courage Of Being
}

\author{
Joyce Gonçalves Restier da Costa Souza ${ }^{1}$
}

\section{RESUMO}

As discussões sobre liberdade, igualdade e solidariedade estiveram presentes na constituição da sociologia clássica independente de sua escola. A modernidade surgiu transformando a sociedade pelos meios de produção e pelas novas relações sociais que se estabeleciam. O Capitalismo visto como o sistema gestor da Modernidade ocasionou a ênfase das modificações estruturais na sociedade sob o crivo da economia, detendo em si, a escravização e a especificidade do papel da violência como agente histórico determinante propiciando a acumulação de capital que engendrou a Revolução Industrial. Imbuídos desta noção argumentaremos a partir de configurações sobre corporeidades negras a possível produção de sentidos sobre a liberdade a partir dos corpos de mulheres negras.

PALAVRAS-CHAVE: Liberdade; Igualdade; Corporeidade Negra; Mulheres Negras.

\begin{abstract}
Discussions on freedom, equality and solidarity were present in the constitution of classical sociology independent of his school. Modernity emerged by transforming society by the means of production and by the new social relations that were established. Capitalism, seen as the management system of modernity, has given rise to the emphasis of structural changes in society under the scrutiny of the economy, holding in itself the enslavement and specificity of the role of violence as a decisive historical agent, propitiating the accumulation of capital that engendered the Industrial Revolution. Imbued with this notion we will argue from configurations on black corporeities the possible production of meanings about freedom from the bodies of black women.
\end{abstract}

KEYWORDS: Freedom; Equality; Black Corporeity; Black Women.

\footnotetext{
1 Mestranda em Ciências Sociais pela PUC-Rio; Mestre em Relações Étnico-Raciais pelo CEFET/RJ e Licenciada em Educação Física. E-mail: joyce.grsouza@gmail.com
} 


\section{INTRODUÇÃO}

As discussões sobre liberdade, igualdade e solidariedade estiveram presentes na constituição da sociologia clássica independente de sua escola. A modernidade surgiria como um novo paradigma transformando as estruturas sociais, principalmente, a partir de seus meios de produção e pelas novas relações sociais que se estabeleciam. Se visualizarmos o capitalismo como o sistema gestor da modernidade, como explicita Carlos Moore (2012), perceberemos que as modificações estruturais que se deram na sociedade sob o crivo da economia teriam como meio específico de acumulação de capital, para engendrar a Revolução Industrial, a escravização dos povos africanos e a especificidade do papel da violência como agente histórico determinante.

Iniciamos nosso debate trazendo à tona o entendimento sobre o que seriam os textos clássicos. Segundo Calvino (2007, p.10), textos clássicos são aqueles que "exercem uma influência particular quando se impõe como inesquecíveis e também quando se oculta nas dobras da memória, mimetizando-se como inconsciente coletivo ou individual". Desta forma ao selecionarmos os clássicos da teoria sociológica tendemos a utilizar aqueles conceitos descritos pelos autores que se tornaram base para a fundamentação de alguma compreensão da realidade. Em nosso texto elencamos as percepções sobre liberdade e igualdade desenvolvidas por Jean Jacques Rousseau e Alexis de Tocqueville.

Nossa questão perpassa as explanações dos referidos autores sobre liberdade e igualdade imersos em sua realidade social, caracterizada pela privação de direitos civis e liberdade de ação para uma parcela da população mundial, os povos africanos escravizados. Assim, "se as convenções linguísticas de um dado período revelam o universo intelectual de qualquer obra histórica particular" (ALEXANDER, 1999, p.76), buscamos por meio da interpretação destes conceitos, considerados fundamentais, a base de uma percepção e dos conflitos que a realidade social pode ter gerado na composição destes.

Imbuídos desta compreensão argumentaremos, a partir de noções sobre corporeidade, a possibilidade de produção de sentidos sobre a liberdade e igualdade para a construção de uma corporeidade negra diaspórica, onde a ressignificação de signos e a comunicação não verbal 
estiveram como representação de um texto compartilhado no encadeamento das manifestações corporais compartilhadas entre escravizados e seus descendentes.

Nosso objetivo está em elucidar a relação entre corpo e liberdade por meio da compreensão das diferentes possibilidades de corporizações de discursos em dada realidade social.

\section{A LIBERDADE EM ROUSSEAU}

Jean Jacques Rousseau viveu durante o século XVIII (1712-1778), porém sua obra atravessou os séculos sendo utilizada como base para a fundamentação dos direitos humanos na modernidade. Sua formulação é de tamanha importância que Émile Durkheim² “concedeu-lhe o título de precursor da sociologia e Claude Levi-Strauss ${ }^{3}$ disse ser ele o fundador das ciências do homem" (ROMÃO, 2009: p.150).

Rousseau trabalha com a categoria hipotética na descrição de suas formulações e com isso descreve o Estado de Natureza ${ }^{4}$ como dois momentos no qual o homem natural se torna homem civil. Diferentemente de Thomas Hobbes ${ }^{5}$ e John Locke ${ }^{6}$, o autor vê o Estado de Natureza como um momento onde o homem obteve sua felicidade plena devido ao fato de não sofrer as influências do meio social, vivendo isoladamente por meio de seus instintos (ROMÃO, 2009: p.158).

Nesta leitura "o ser que habita o estado de natureza é também marcado pela liberdade e pela igualdade" assim como "não há como distinguir os homens se não há nada que os limite ou diferencie", o único limite possível "é o uso da razão" (ROMÃO, 2009: p.161). Dentro deste modelo, todos têm direito a tudo sendo a razão a única prática capaz de criar diferenciações e limitações à liberdade. Já em Xirau (2015: p.30, grifo do autor), observamos que a liberdade natural em Rousseau seria a ausência de compulsão e "também é a máxima dependência; é a 'dependence des choses' e dos homens considerados como coisas; é o domínio da pura força física".

2 (1858-1917); Um dos principais expoentes da sociologia ao lado de Max Weber e Karl Marx.

3 (1908-2009); Antropólogo, fundador da antropologia estruturalista.

4 (1588-1679); Filósofo, explanou sobre a natureza humana.

5 (1632-1704); Filósofo, ideólogo do liberalismo, fundador do contrato social.

6 Expressão usada para definir uma situação na qual os homens viveriam de acordo com sua razão, seus instintos/desejos guiados por direitos naturais. 
Em nossa percepção, analisamos a questão colocando em pauta o contexto histórico no qual vivia Rousseau. Século XVIII tínhamos a escravidão negra e as "descobertas" no Novo Mundo como parâmetro referencial para distinção entre os homens, seja pela raça, pela etnia ou pela cultura. Acompanhando o pensamento de Guimarães (2013, p.02), entendemos que "a ideia de raça, na verdade, como uma construção pseudocientífica, política, mobilizada à época da institucionalização da sociologia para a consolidação dos impérios europeus e sua expansão ultramarina" esteve conectada com a realidade social dos autores clássicos e por esta razão questionamos, mesmo sendo hipotéticas as proposições de Rousseau, como poderia o homem ser livre mantendo a dependência das coisas ou de homens considerados coisas e ainda, qual seria a liberdade e a igualdade para esses homens considerados coisas? Visualizamos juntamente com Xirau (2015) o enorme esforço de Rousseau em encontrar um conceito de liberdade que concilie a vida em sociedade, segundo ele:

Tal renúncia (da liberdade) é incompatível com a natureza do homem. Rouba às suas acções todo o sentido moral, quem retira do seu querer toda a liberdade. Enfim, é uma convenção contraditória e vã, aquela que estipula, por um lado, a autoridade absoluta e, por outro, uma obediência sem limites (ROUSSEAU, 2010: p.22)

Nesta passagem encontramos o esforço discursivo da conceituação de liberdade, afinal, como explicar a submissão dos povos africanos se a renúncia à liberdade é algo incompatível à natureza humana? Seriam eles coisas ou animais como defendia a ciência biológica à época? A grandiosidade da discussão em $\mathrm{O}$ Contrato Social surge quando este condena o direito de conquista em uma guerra, e esta também é condenada por ser algo criado pelas relações entre os homens e estar voltada do Estado para o Estado, o que não deveria resvalar em seus vassalos. Logo:

\footnotetext{
Se a guerra não dá ao vencedor o direito de trucidar os povos vencidos, igualmente não lhe concede o direito de os dominar. Só permitido matar o inimigo quando não é possível fazê-lo escravo; portanto o direito de escraviza-lo não deriva do direito de o matar. É uma troca iníqua obriga-lo a vender a sua liberdade, a troco de uma vida sobre a qual não se tem qualquer direito. Ao estabelecer-se o direito de vida e de morte sobre o direito de escravatura e o direito de escravatura sobre o direito de vida e de morte, não surge como evidente que se está caindo num círculo vicioso? [...]. Aceitando até o terrível direito de tudo matar, eu afirmo que um escravo de guerra ou um povo conquistado só deve obedecer ao senhor enquanto for obrigado. Porque o vencedor não lhe perdoou. Encontrou uma vantagem ao conceder-lhe a vida, em vez de o matar sem qualquer proveito (ROUSSEAU: 2010, p.25)
} 
Encontramos nesta passagem uma certa condenação dos meios de escravização por estes anular os direitos de vida dos acometidos. A liberdade seria então o bem maior que confere a plenitude ao homem, argumentando que a razão e a alienação seriam a grande causa das desigualdades e da infelicidade do homem civilizado. As convenções acabam por alienar e corromper o homem, "que passa a ter o desejo de ser superior aos outros" (Romão: 2009, p.165), o que geraria a primeira escravidão.

Deste modo, o humanismo em Rousseau trata o homem como ser capaz de superação das adversidades da natureza, o que o leva ao conceito de perfectibilidade, ou seja, "a capacidade de aperfeiçoar-se". Dito isso, segundo Lilia Schwarcz (1993: p.45), "pressupor a igualdade e a liberdade como naturais levava à determinação da unidade de gênero humano e a certa universalização da igualdade, entendida como um modelo imposto pela natureza". E ainda: "Marca de uma unidade una, mas diversa em seus caminhos, a 'perfectibilidade humana' anunciava para Rousseau os 'vícios' da civilização, a origem da desigualdade entre os homens" (SCHWARCZ, 1993: p.44). Concluímos então que Rousseau acreditava que a civilização e os meandros de sua estruturação eram a causa das desigualdades entre os homens. O seu humanismo procurava "na identificação, ou 'na compaixão', a melhor maneira de entender esse homem que tanto se distinguia da experiência ocidental" (SCHWARCZ, 1993: p.45).

\section{LIBERDADE EM TOCQUEVILLE}

De família aristocrata, Alexis de Tocqueville (1805-1859), teve como uma das bases para a formação de seu pensamento a perspectiva germânica da Querela das duas Raças reescrita por Henri de Boulainvilliers?. A autora Helga Gahyva (2012, p.171), identifica nesta perspectiva "a gênese de uma tripla polaridade que informa a perspectiva tocquevilliana: em um eixo positivo, liberdade, heterogeneidade e descentralização; no eixo negativo, igualdade, homogeneidade e

7 Conde Henri de Boulainvillers (1658-1722) foi economista e historiador. Reescrevei a romanidade e germanidade nos momentos finais de consolidação da monarquia nacional francesa: a ascendência germânica e as prerrogativas dela derivadas tornavam-se patrimônio exclusivo da aristocracia. Ver em: GAHYVA, 2012, p.171. 
centralização", que "contribuiu para limitar a consciência possível nas tentativas de compreender o surgimento e os rumos da nova ordem igualitária que vira emergir”.

A liberdade para Tocqueville estava pautada no âmbito político no qual a maior participação na vida pública e consciência política levaria o homem à liberdade. "A pujança da atividade política servia de índice para avaliar o grau de liberdade de uma dada formação social" (JASMIN, 1997: p.52). Assim, o modelo americano com suas associações e descentralização do poder, que garantiriam a representação de todos no Estado, foi caracterizado como exemplo para a Democracia, com normatização legal das instituições haveria de ser garantida a liberdade individual e a igualdade de condições sociais: "uma igualdade que se realiza e que se expande gradualmente na letra da lei” (GAHYVA, 2006: p.575).

Para Tocqueville, segundo Frey (2000: p.113), a democracia não corresponderia apenas a um certo sistema político, mas a um "peculiar modo de vida" que valorizasse o bem comum e a virtude pública. Seria a "igualização crescente das condições políticas e sociais entre os homens" (FERREIRA, 2009: p.257). Desta maneira, nosso autor tem uma visão otimista das possibilidades da igualdade em termos de condições políticas e sociais. Mas quem seriam os reais portadores de condições à igualização?

Avaliando esta assertiva dentro da nossa percepção sócio-histórica, como observar a igualização das condições sociais com a ampla escravidão em operação como modo de produção capitalista? Questionamos assim a frase de Gahyva (2006) quando a autora expõe a perspectiva tocquevilliana com foco nas desigualdades e não na permanência de privilégios. De acordo com o próprio Tocqueville, na América, se impõe um estado social extraordinário: "Lá veem-se homens com maior igualdade em ponto de fortuna e intelecto, ou, por outras palavras, mais iguais em sua força, do que em qualquer outro país do mundo, ou em qualquer idade da qual a história tenha preservado a lembrança" (TOCQUEVILLE apud FERREIRA, 2009). A igualdade entre os norte-americanos estaria assim pautada em suas posses, consequentemente em seus privilégios e é justamente nesse prisma que a autora coloca a herança germânica que insiste em subsidiar Tocqueville.

De acordo com Carlos Moore (2012: p.197), as desigualdades sociais desdobram-se em iniquidades raciais, que por sua vez, reforçam as diferenças. Portanto, quando os homens democráticos têm como característica preponderante a preferência pela igualdade em detrimento da liberdade, este é um argumento que se justifica da seguinte maneira: 


\begin{abstract}
Para um povo democrático destruir a igualdade, seria preciso que modificasse seu estado social, abolisse suas leis, renovasse suas ideias, mudasse seus hábitos, alterasse seus costumes. Mas para perder a liberdade política, basta não conservá-la, e ela escapa. Os homens não se apegam a determinada instituição, como a igualdade, apenas porque a querem: apegam-se a ela ainda porque creem que deve durar sempre (JASMIN,1997: p.47).
\end{abstract}

Percebemos que as diferenças impostas aos seres humanos no século XIX, reforçam as diferenças, e mais, pretendem negar estruturalmente o acesso o usufruto dos recursos da sociedade para uma parcela dela, diferenciada racialmente. A igualdade seria ainda para o povo democrático uma maneira de manter seus privilégios e leis que resguardavam principalmente sua posição social e o acesso aos recursos da sociedade. Desta maneira, seguindo ainda o pensamento de Carlos Moore, postulamos o fato da igualdade em termos democráticos estar em concomitância com o objetivo de "estruturar o conjunto de relações sociais, políticas e interpessoais entre grupos humanos fenotipicamente diferenciados, mas obrigados a conviver de forma assimétrica na mesma sociedade, a saber, em situações de iniquidade em todos os aspectos" (JASMIN, 1997).

O que caracterizaria uma faceta do racismo perpetrado no século XIX. Mesmo quando Tocqueville investe na concepção de que a liberdade seria possível por meio de modificações graduais, com a educação, isso quer dizer, transformando progressivamente leis e costumes, ainda assim a igualdade social não seria possível. Pois o mesmo vê "no caráter, no espírito e nos costumes, os fatores transformadores da sociedade" e ressalva "os costumes como o único poder firme e durável num povo" (FREY, 2000: p.114). Assim, como modificar os costumes que tem fundamentação em "ideologias sociorraciais que regem e padronizam a vida cotidiana entre todos os segmentos fenotípicos envolvidos em uma experiência de coexistência no contexto de uma sociedade multirracial de desiguais" (MOORE, 2012: p.197)

Tocqueville (2005: p.373) encara a presença de duas raças (indígenas e negros) como aqueles representam os problemas americanos, que são "americanos sem ser democráticos". Em seu volume I de A Democracia nas Américas faz uma explanação sobre as consequências da escravidão negra para EUA, atentando para as implicações tanto da abolição quanto da manutenção da escravidão num paralelo entre o Norte e o Sul americano. A abordagem do autor tem um enfoque nos efeitos da escravidão para a população negra e na iminência de sua libertação, vejamos: 


\begin{abstract}
Se se torna livre, a independência muitas vezes lhe parece um grilhão ainda mais pesado que sua própria escravatura; pois, no curso de sua existência, aprendeu a submeter-se a tudo, exceto à razão; e, se a razão se tornasse seu único guia, não saberia reconhecer a voz. Mil novas necessidades o assediam, e faltam-lhe os conhecimentos e a energia necessários para resistir a elas. As necessidades são amos que cumpre combater, mas ele aprendeu apenas a submeter e a obedecer. Chegou, então, a este cúmulo de miséria, em que o cativeiro o embrutece e a liberdade o faz perecer (TOCQUEVILLE, 2005: p.375).
\end{abstract}

Assim sendo, avaliando as realidades do Norte e do Sul do país, o autor revela ser "o mais temível de todos os males que ameaçam o futuro dos Estados Unidos vem da presença dos negros em seu solo" (TOCQUEVILLE, 2005: p.394). Ocasionado principalmente pela incompatibilidade de união entre brancos e negros, assim diz: "os que esperam que os europeus se confundirão um dia com os negros, parece-me, pois, acalentar uma quimera. Minha razão não me leva a crer nisso, e nada vejo que o indique nos fatos" (TOCQUEVILLE, 2005: p.396). Seu pessimismo advém do preconceito que assistiu enquanto avaliava a escravidão no contexto da sociedade igualitária e democrática e esse preconceito é relatado pelo autor como um costume, algo "imóvel".

Parte então para a analise dos efeitos que o sistema produziu nas propriedades matérias dos envolvidos. Para ele os americanos no Norte aproveitando a quantidade de negros libertos foi, gradualmente, abolindo a escravatura, enviando os escravizados restantes para o Sul. Enxergava claramente o fato dos americanos do Norte prezarem pela individualidade, pela captação de capital e assim recorreriam ao pagamento pelo trabalho prestado e não pelo sustento de escravizados, o que abriu o comércio e dinamizou a economia. Já no Sul do país o investimento em escravizados fazia com que houvesse um menor esforço em empreendimentos mantendo a atividade agrícola, altamente dependente de mão-de-obra.

Daí justifica-se a passagem no qual Tocqueville, segundo Ferreira (2009: p.269), manifesta o argumento de "indenizar os antigos proprietários no caso da abolição em colônias africanas". De acordo com o próprio, manter escravizados gerava um custo econômico maior do que ter operários livres, a indenização seria então uma reparação pelos investimentos prestados à nação, vejamos:

O operário livre é pago, mas trabalha mais depressa que o escravo, e a rapidez da execução é um dos grandes elementos da economia. O branco vende seu auxílio, mas este só é comprado quando é útil; o negro nada tem a reclamar como preço de seus 
serviços, mas seu amo é obrigado a alimentá-lo o tempo todo, [...]. O operário livre recebe um salário; o escravo, uma educação, alimentos, cuidados e roupas. [...] na realidade, o escravo custou mais que o homem livre, e seu trabalho foi menos produtivo (TOCQUEVILLE, 2005: p.401).

O orgulho racial também é apontado por Tocqueville como possível obstáculo à igualdade entre negros e brancos:

De todos os europeus, os ingleses são os que menos misturaram seu sangue ao dos negros. [...]. Esse orgulho de origem, natural do inglês, é singularmente acentuado no americano pelo orgulho individual que a liberdade democrática faz nascer. O homem branco dos Estados Unidos tem orgulho de sua raça e de si mesmo (TOCQUEVILLE, 2005: p.412).

Deste modo, o autor crê que as duas raças (brancos e negros) jamais chegarão a viver em pé de igualdade. Para ele, "enquanto a democracia americana permanecer à frente dos negócios, ninguém ousará tentar semelhante empresa (confundir americanos e seus antigos escravos sob o mesmo jugo), e podemos prever que quanto mais os brancos dos Estados Unidos forem livres, mais procurarão se isolar" (TOCQUEVILLE, 2005: p.411)

Corroborando com a gravidade da situação da liberdade e da igualdade na América, Carlos Moore (2012: p.170), ressalva o fato que a escravidão americana se distingue fundamentalmente, de todas as formas de escravidão que a antecederam na história, o que também é colocado por Tocqueville (2005: p.394), "trata-se da primeira experiência na história em que uma raça inteira foi especificamente almejada para a escravidão".

Por fim:

A partir do momento em que os europeus fizeram escravos no seio de uma raça de homens diferente da sua, que muitos deles consideravam inferior às outras raças humanas e à qual todos encaram com horror a hipótese de se assimilar um dia, supuseram a escravidão eterna; porque entre a extrema desigualdade que a servidão cria e a completa igualdade que a independência produz naturalmente entre os homens, não há estado intermediário que seja duradouro. Os europeus sentiram vagamente essa verdade, mas sem confessá-la a si mesmos. Todas as vezes que se tratou dos negros, vimo-los obedecerem ora a seu interesse ou a seu orgulho, ora à sua piedade. Eles violaram, em relação ao negro, todos os direitos da humanidade, e, depois, instruíramno sobre o valor e inviolabilidade desses direitos. Abriram seu meio a seus escravos e, quando estes tentavam entrar, expulsaram-nos com ignomínia. Querendo a servidão, deixaram-se levar, contra a sua vontade ou sem o saber, em direção à liberdade, sem ter a coragem de ser nem completamente iníquios nem inteiramente justos (TOQUECVILLE, 2005: p.418-19). 


\section{O CORPO E A CORPOREIDADE NEGRA}

O corpo como depositário da cultura, tem em suas expressões os códigos e signos linguísticos adquiridos mediante o convívio em sociedade e é por intermédio deste convívio que fixam-se as memórias, trajetórias de vida, origens e posição social dos sujeitos. Os comportamentos dos círculos sociais também são incorporados estabelecendo entre a sociedade e o corpo uma mediação onde a cultura e a expressão tornam-se textos no qual os gestos são signos passíveis de interpretações através da linguagem corporal.

A corporeidade como agir no mundo, seria a relação com outros corpos e com as coisas do mundo, a complexidade do entendimento do ser/estar. A vivência corporal carregada de movimentações simbólicas, caracteriza e situa a presença no mundo, compondo uma gama de signos e representações sobre o Eu e os Outros, alicerçando as diferenças. Ao estabelecer os limites e as fronteiras entre o Eu e o que não faz parte dele se constitui socialmente a diferença, através de interpretações e reinterpretações dos sistemas de representação e classificação existentes em sua cultura.

A cultura nas sociedades é expressa pelos corpos de seus indivíduos, o corpo cidadão se torna um arcabouço de símbolos e singularidades culturais do local e do tempo onde vive. Sendo assim, entender o corpo como matéria sociológica é ter em mente esta contribuição da cultura, da educação e consequentemente da política na formação deste cidadão, na constituição de sua corporeidade como sujeito social e das identidades coletivas deste.

Apreendendo o corpo e suas representações enquanto construção social, buscamos a compreensão sobre a produção de sentidos sobre a corporeidade no cotidiano através de sua movimentação simbólica. A interpretação dos textos corporais nos remete ao lugar do corpo enquanto prática discursiva, posto que as práticas discursivas "são as linguagens em ação, as maneiras pelas quais as pessoas produzem sentidos e se posicionam em relações sociais cotidianas" (SPINK, 2013: p.26).

A produção de sentidos no cotidiano através dos corpos é realizada por meio da corporeidade, na atuação corpórea e simbólica no tempo, no espaço e em sociedade. "O sentido é uma construção social interativa por meio da qual as pessoas constroem os termos a partir dos 
quais compreendem e lidam com as situações e fenômenos a sua volta (SPINK, 2013: p.22), estando presente todo o tempo, na história e nas percepções de vida de cada participante da interação.

Para tal interação, temos inscritos no corpo, muitos códigos de comunicação. A fala, os gestos, as características físicas são alguns deles. Como agente cultural, o corpo, acaba por ser o veículo de comunicação dos indivíduos, considerando que antes, durante e após a fala temos posturas e atitudes corporais que afirmam ou negam o que é dito. Compreendemos como parte das linguagens corporais: os gestos, a atitude corporal, assim como as características marcantes que diferenciam este corpo de outros. Composta a corporeidade, esta se torna o código hiperlinguístico deste corpo, por ser uma estrutura simbólica, suas representações são significações para os grupos que compartilham tal linguagem e por esta razão, são os seus repertórios utilizados como signos de identidade social, compondo um discurso sobre o grupo.

A identidade social dos indivíduos seria a primeira relação da corporeidade com mundo. Se estabelece na relação dialógica entre os grupos sociais e seus discursos. Entendemos então, a identidade como algo fluido, que se molda a partir dos dialogismos e da interação social com os diferentes discursos que se instituem em uma sociedade. A questão da identidade não é um perfil essencializante e sim uma condição de identificação, onde ao incorporar a linguagem do grupo social ao qual faz parte, seus discursos se tornam representatividade na corporeidade do sujeito. A corporização dos discursos dos grupos sociais realiza a ação de tornar visível as particularidades culturais, estando estas particularidades diretamente relacionadas com a identidade de tais grupos. Assim, como ressalta Souza (2009, p.38), "a ideia de identidade se marca pela compreensão de que existe uma diferença que permite o balizamento daquilo que é distinto para se estabelecer o que é igual." enaltecendo a importância dos processos de diferenciação no estabelecimento das identidades sociais.

Seguindo a observação de Stuart Hall (2013a: p.06) podemos enxergar o corpo como um texto, um texto pronto para ser lido e interpretado. Um texto que, segundo Franz Fanon (2008: p.104), tratando-se da população negra, já tem uma leitura pronta, que é aquela do observador branco: "Pois o negro não tem mais de ser negro, mas sê-lo diante do branco". Atentamos, então, para o fato do corpo, enquanto texto, ser construído a partir do que se assiste dele, do que se sabe sobre ele e também sobre o que é dito sobre ele. 
A construção do corpo, com vimos, organiza-se socialmente. As concepções que aprendemos e dispusemos como conhecimento são adquiridas como consequência da mediação entre corpo e cultura, sendo esta responsável por moldar os sujeitos e seus corpos de acordo com discursos e normas sociais de cada sociedade, pois como nos alerta Rodrigues (2006: p.123), "é a sociedade que manipula o corpo para expressar-se."

A produção de sentidos sobre a população negra tem em seus repertórios os significantes sobre o Ser Negro. Significantes específicos da condição sócio-histórica dos negros e negras em sua sociedade diaspórica, convergindo concepções sobre a ancestralidade africana, a escravidão e o diálogo com a cultura europeia. A interpretação sobre os corpos de negros e negras obteve a base de sua estruturação nos estereótipos disseminados pelo discurso europeu, restando aos sujeitos aos quais este discurso difamavam ressignificar seus signos a fim de constituir uma linguagem contra hegemônica que representasse sua identidade.

O valor social dos aportes identitários para a população negra, como o corpo e o cabelo crespo, são tanto objetos de identificação e resgate da ancestralidade africana quanto objetos de rejeição passando por reinterpretações ancoradas no branqueamento com a pretensão de inserção social. Dito isso, é necessária a compreensão da significância destes objetos para a população em questão.

Referindo-se a sociedade brasileira, observamos que nesta, alicerçada em um pensamento social onde as teorias racistas do XIX, a eugenia e a democracia racial foram preponderantes em sua organização, o corpo e sua linguagem tornaram-se mecanismo de leitura da realidade social de seus indivíduos, cabendo às características físicas, posturas, atitudes e comportamentos sociais serem interpretados como retrato da realidade social dos sujeitos que a expressam. É neste ensejo que enxergamos as condições nas quais os corpos de negros e negras foram interpretados na sociedade brasileira.

Como bem expõe Stuart Hall (2013b: p.324) "dentro de toda exclusão e opressão sofrida na colonização, restou às populações de descendência africana o seu corpo como forma de expressão e significação na diáspora" tornando assim, os corpos de afrodescendentes, um espaço de significação onde memórias, tradições, valores, posição e situação social são evidenciados e interpretados a partir de seus gestos, atitudes corporais e características físicas. O corpo negro com todas as suas manifestações corporais se torna um discurso pela liberdade e pela cidadania, 
assim como uma denúncia à exclusão social e ao abandono das autoridades políticas na integração da população negra.

\section{A CORPOREIDADE E O DISCURSO DA LIBERDADE: A CORAGEM DE SER - MULHERES NEGRAS}

Em todo o contexto histórico que descrevemos, seja na França oitocentista de Rousseau, na América do século XIX de Tocqueville e até mesmo na sociedade brasileira, encontramos a escravidão negra como ponto em comum. Nesta parte do texto traremos a reflexão sobre como a noção de liberdade cunhada até aqui pela Europa Ocidental, poderia ter uma outra expressão no entendimento dos povos afro-diaspóricos. Não nos dispomos a trazer traços de um pensamento africano, mas sim, reflexões sobre a corporeidade negra que evocam um comportamento diferenciado sobre o referido conceito.

As mulheres negras que foram escravizadas passaram, segundo Gizêlda Nascimento (2008: p.50), por um contexto que ela denominou como espaço de falta. O argumento da autora se refere ao fato destas mulheres apenas acumularem perdas, seja em nível racial, social ou sexual, que caracterizaria a sua dificuldade de inserção nos quadros sociais representativos. Assim, estas mulheres tiveram que, na complexidade de sua sobrevivência, restaurar padrões de comportamento e ressignificar suas percepções sobre a vida, adaptando-se a violenta realidade na qual viviam.

\footnotetext{
Todo arcabouço trazido pela mulher africana estava enraizado em suas estruturas cognitivas, orientando sua percepção do mundo. Essas mulheres cultivavam um entendimento próprio, e bem diferente, do que eram as relações entre homens e mulheres. Somava-se a esse entendimento a concepção que elas traziam de si mesmas como protagonistas não apenas de sua própria vida, mas também de uma sociedade inteira (BONFIM, 2009: p.239).
}

Segundo Ida Mara Freire (2008: p.05), “a coragem é necessária para que a mulher possa ser e vir a ser. Para que o eu seja é preciso afirmá-lo e comprometer-se". Deste modo, ao comprometerem-se como guardiãs das tradições e até mesmo como arrimo de suas famílias, estas mulheres demonstraram a coragem em serem livres, em ter na sua corporeidade a liberdade 
conceitualmente defendida. Chegamos a este entendimento a partir da reflexão da autora quando ela esclarece que "a liberdade desvela, ao mesmo tempo, tanto a singularidade quanto a identidade. Pois ser livre atravessa o ser em si mesmo, cujo domínio é o mundo” (Freire, 2015: p.38).

Assim a corporeidade de mulheres negras por meio de suas ações, cantos, danças, demonstrava a sua capacidade de estar no mundo. Seu corpo vivido, a experiência, juntamente com sua memória corporal possibilitava sua relação de liberdade com o seu corpo, seu pensamento, com a sua vida. As reelaborações que realizaram em algumas de suas práticas culturais: "religiões de matriz africana, modos de vestir e falar, arranjos familiares matricêntricos, relação não tabuizada com o corpo, constituíram brechas estabelecidas na estrutura social, segundo a dinâmica dominação-resistência” (NASCIMENTO, 2009: p.239).

Para elucidar a conexão entre corporeidade e o conceito de liberdade, utilizaremos a noção de liberdade de Maurice Merleau-Ponty, acompanhada da profunda reflexão realizada por Ida Mara Freire sobre a dança e o conceito de liberdade no contexto sul africano. Segundo a autora, a dança é uma forma de comunicação, de expressão de sentimentos e crenças; é uma maneira de preservar a história e as tradições culturais, "um modo de viver inteiro e complexo" (2015, p.38). Assim, a dança se traduz em gestos que "produzem sensações de jubilo e potência que conferem dignidade ao corpo negro" (PETIT E CRUZ, 2008: p.05), é a sua conexão com o sagrado. E o sagrado para um sujeito desterritorializado, como no caso em questão, seria o seu próprio corpo, o corpo-território.

Assim, as mulheres negras tinham em seu corpo-território a sua liberdade, afinal como o conceito é condicionado historicamente, ele "somente existe em contato com o mundo" (FREIRE, 2015: p.40), ou seja, por meio da privação das liberdades individuais e coletivas, estas mulheres, sujeitos de sua história, reelaboraram o ser livre a partir de sua experiência e o seu mundo de significados. Assim, "a liberdade se embaraça nas contradições do envolvimento, e que não se percebe que ela não seria liberdade sem as raízes que lança ao mundo" (MERLEAUPONTY apud FREIRE, 2015).

Desta maneira, concordamos em observar as manifestações corporais de mulheres negras africanas e diaspóricas como uma expressão de liberdade onde sua corporeidade esbanja todo a sua compreensão sobre a vida e o mundo no qual vive, sobrevive e desafia aos padrões normativos com sua audaciosa vitalidade. O que nos aponta para uma insistente reiteração de 
discursos estereotipados na tentativa de mantê-las em subalternidade, independentemente de sua condição econômico-social.

Estas mulheres são visualizadas por meio de sua cor e com isso são enquadradas em diversas categorias pejorativas que alimentam as discriminações sociais e raciais. Seu comportamento ativo e altivo, sua independência da rigidez das normas sociais e principalmente a sua inesgotável disposição em ter em seu corpo a representação de sua liberdade e sua estética, conferem às mulheres negras o status de alvo das constituições discursivas etnocêntricas e racistas.

Em nosso país, vê-se recentemente muitas críticas, não novas, sobre as expressões de uma corporeidade negra, dita periférica e marginalizada. Se analisarmos com cuidado perceberemos que estas críticas recaem sobre as mulheres negras, mas não só sobre o sujeito mas principalmente sobre o seu corpo. Seja como mulata, como gorda, como sexy, como feia, dentre outras adjetivações, as mulheres negras em razão de sua liberdade é acometida pelos discursos de ódio e racistas, mantendo ainda hoje, uma premissa iniciada no século XVIII com Saartijie Baartman ${ }^{8}$ (Vênus Negra), tendo a sua exuberância utilizada como modelo negativo à normalidade aos homens e mulheres brancos.

Por fim, uma parte da corporeidade negra brasileira, pode ser descrita a partir do corpoterritório de suas mulheres. A vanguarda da emancipação negra, mulheres trabalhadoras, mães biológicas, de leite, "por extensão", de santo e de criação. Responsáveis pela preservação da tradição e dos segredos que transformam o poderoso feminino em sagrado.

\section{CONSIDERAÇÕES FINAIS}

8 Saartjie Baartman, nascida em 1789, na África do Sul, segundo Braga (2015, p.39) pertencia ao povo Khoisan, considerada a mais antiga etnia humana estabelecida da parte meridional da África. Foi adotada aos 10 anos por uma família de agricultores holandeses na condição de serva e por não saberem o nome de batismo foi chamada de Saartjie (pequena Sarah), herdando o sobrenome da família adotiva Baartman. Sobre a história de Saartjie, ver Damasceno, Janaína. "O corpo do outro. Construções raciais e imagens de controle do corpo feminino negro: O caso da Vênus Hotentote".

9 Termo utilizado por Édouard Glissant na descrição das familias negras na Martinica em contraposição ao modelo nuclear ocidental (Nascimento, 2009, p.54). 
Com a intenção de discutir conceitos fundamentais para os teóricos clássicos das ciências sociais, utilizamos as percepções de Rousseau e Tocqueville sobre Liberdade e Igualdade em seus escritos. Seguindo o pensamento de Jeffrey Alexander (1999), onde o verdadeiro significado de um texto, em parte, também é determinado pela situação histórica do intérprete e pela totalidade do curso da história, efetuamos uma leitura sobre os conceitos a partir do dilema do período em que nossos autores viveram: A escravidão.

A escravidão negra esteve presente na constituição da maioria das novas ciências dos séculos XVIII e XIX. Diante disto é de relevância apresentar os conceitos propostos trazendo, a escravidão, como dilema tanto na constituição das teorias quanto no desenvolvimento dos discursos dos autores. Ao mesmo tempo em que refutam as formas de preconceito e prezam pela igualdade dos seres humanos, a matriz etnocêntrica de sua formação impede a plena continuidade de suas formulações. Em algum momento, o "Outro" se diferencia demais do "Nós", ratificando de alguma maneira, o que estariam dispostos a refutar.

Negar esta condição seria o mesmo que invisibilizar o discurso proferido por estes corpos a cada momento em que seus gestos, suas danças e sua beleza invadem os espaços sociais antes ocupados apenas por outros grupos sociais. Negar esta condição seria não reconhecer a liberdade como condicionada, como algo que é referenciado na interação com outro.

A corporeidade negra então, luta em prol da diferenciação sim, pelo respeito à sua individualidade e pela sua fixação no cotidiano, modificando seus discursos e impregnando seus repertórios de representatividade.

Discutir essas perspectivas pode elucidar novas concepções sobre os clássicos e permitir, no nosso caso, a confirmação de discursos proferidos por autores outsiders que permanecem no ostracismo mesmo com fidedignidade intelectual. O reconhecimento social e político destes autores pode ser oportunizado por iniciativas de debate com os clássicos. Bem como Jeffrey Alexander (1999) compreendemos como objeto das ciências sociais, a vida, assim sendo, é necessário ter como fim do debate intelectual nas ciências sociais a possibilidade de transformação da realidade social por meio da argumentação discursiva, a qual, a privação da liberdade e da igualdade de condições sociais nos impediu durante algum tempo.

Submetido para avaliação 28 de fevereiro de 2018 Aprovado para publicação em 17 de setembro de 2018 


\section{BIBLIOGRAFIA}

ALEXANDER, Jeffrey. (1999), “A importância dos clássicos”. In: A. GIDDENS e J. TURNER. Teoria Social Hoje. São Paulo, UNESP, pp. 23-89.

BONFIM, Vania M. (2009), "A identidade contraditória da mulher negra brasileira: Bases históricas." In: E. NASCIMENTO(Org). Afrocentricidade: Uma abordagem epistemológica inovadora. São Paulo, Selo Negro, (Sankofa: Matrizes africanas da cultura brasileira 04), pp.219 149.

CALVINO, Ítalo. (2007), Por que ler os clássicos. São Paulo, Companhia das Letras.

FANON, Franz. (2008), Pele Negra, Máscaras brancas. Salvador, UFBA.

FERREIRA, Lier. (2009), "Alexis de Tocqueville: O argumento liberal de defesa da liberdade". In: __ et al.(orgs.). Curso de Ciência Política: Grandes autores do pensamento político e contemporâneo. Rio de Janeiro, Elsevier, pp. 251-290.

FREIRE, Ida Mara. (2008), "O feminino e o sagrado na dança: um ensaio sobre a coragem de ser”. Anais do VIII Seminário Internacional Fazendo Gênero, pp.01-07. Acessado em 20/01/2018 e disponível em:

http://www.fazendogenero.ufsc.br/8/sts/ST22/Ida Mara Freire 22.pdf

. (2015), Toyi-Toyi: A dança de uma nação e a noção de liberdade em Merleau-Ponty.

In: C. SILVA e M. MULLER (Orgs.). Merleau-Ponty em Florianópolis. Porto Alegre, Editora Fi, pp.37-55.

FREY, Klaus. (2000), "Descentralização: Lições atuais de Tocqueville”. Lua Nova: Revista de Cultura e Política, no 51, pp. 97-119. Acessado em 05/08/2017 e disponível em: http://dx.doi.org/10.1590/S0102-64452000000300007

GAHYVA, Helga. (2006), “Tocqueville e Gobineau no mundo dos iguais”. Dados: Revista de Ciências Sociais, vol 49, $\mathrm{n}^{\circ}$ 3, pp.553-582. Acessado em 05/08/2017 e disponível em: http://dx.doi.org/10.1590/S0011-52582006000300005

- (2012), "De Boulainvilliers a Tocqueville: da liberdade como defesa de privilégios à liberdade como defesa de diferenças". Revista Sociologias, ano 14, no 31, pp. 168-190. Acessado em 05/08/2017 e disponível em: http://dx.doi.org/10.1590/S1517-45222012000300008 .

GUIMARÃES, Antônio. (2013), "Sociologia e Raça". XVI Congresso da Sociedade Brasileira de Sociologia, Salvador. Acessado em: 09/08/2017 e disponível em: 
http://www.fflch.usp.br/sociologia/asag/Sociologia $\% 20 \mathrm{e} \% 20 \mathrm{raca} \% 2019032014$. pdf

HALL, Stuart. (2013a), "Raça, o significante flutuante". Revista Z Cultural (PACC-UFRJ), ano VIII, n’.2. Acessado em 09/07/2014 e disponível em:

http://revistazcultural.pacc.ufrj.br/raca-o-significante-flutuante $\% \mathrm{EF} \% 80 \% \mathrm{AA} /$

Editora UFMG.

(2013b), Da diáspora: Identidades e mediações culturais. 2.ed, Belo Horizonte,

JASMIN, Marcelo. (1997), Alexis de Tocqueville: a historiografia como ciência da política. Rio de Janeiro, ACCESS.

MOORE, Carlos. (2012), Racismo \& Sociedade: novas bases epistemológicas para entender o racismo. 2ed, Belo Horizonte, Nandyala.

NASCIMENTO, Gizêlda. (2008), "Grandes mães, reais senhoras”. In: E. NASCIMENTO (Org). Guerreiras da Natureza: mulher negra, religiosidade e ambiente. São Paulo, Selo Negro, (Sankofa: Matrizes africanas da cultura brasileira 03), pp.49 - 63.

ROMÃO, Christiane (2009), "Jean Jacques Rousseau: da inocência natural à Sociedade Política". In: L. FERREIRA et.al.(Orgs.), Curso de Ciência Política: Grandes autores do pensamento político e contemporâneo. Rio de Janeiro, Elsevier, pp. 147-183.

PETIT, Sandra e CRUZ, Norval. (2008), "Arkhé: Corpo, simbologia e ancestralidade como canais de ensinamento na educação". Anais do 310 ANPEd, pp. 01-13. Acessado em 20/12/2017 e disponível em: http://31 reuniao.anped.org.br/1trabalho/GT21-4159--Int.pdf

RODRIGUES, José. (2006), Tabu do Corpo. 7 ed. rev. Rio de Janeiro: Editora FIOCRUZ.

ROUSSEAU, Jean. (2010), O Contrato Social. Acessado em: 25/03/2017 e disponível em: http://www.dominiopublico.gov.br/download/texto/cv00014a.pdf

SCHWARCZ, Lilian. (1993), O espetáculo das raças: cientistas, instituições e questão racial no Brasil (1987-1930). São Paulo, Companhia das Letras.

SOUZA, Patrício. (2009), "Ensaiando a corporeidade: corpo e espaço como fundamentos da identidade". GEOGRAFARES, no 7, pp. 35-50. Acessado em 25/01/2015 e disponível em: http://www.periodicos.ufes.br/geografares/article/view/149/75

SPINK, Mary (orgs). (2013). Práticas discursivas e produções de sentido no cotidiano: Aproximações teóricas e metodológicas. 1.ed., Rio de Janeiro, Centro Edelstein de Pesquisas Sociais (publicação virtual).

TOCQUEVILLE, Alexis. (2005), A Democracia na América: leis e costumes de certas leis e certos costumes políticos que foram sugeridos aos americanos por estado social democrático. 2ed. 
São Paulo, Martins Fontes. Acessado em: 22/09/2016 e disponível em: https://direitasja.files.wordpress.com/2012/05/a-democracia-na-amc3a9rica-vol-i-alexis-detocqueville.pdf

XIRAU, Joaquin. (2015), "Rousseau e as ideias políticas modernas". In: et al. Estudos sobre Rousseau. Rio de Janeiro, Contraponto, pp.11-51. 